\title{
Access Control and Monitoring: A System for Computer Laboratory
}

Daniel B. Zapanta Jr. ${ }^{1}$, Hidear Talirongan ${ }^{2} \&$ Florence Jean B. Talirongan ${ }^{3}$

${ }^{1-3}$ Misamis University, Ozamiz City, Philippines.

DOI: http://doi.org/10.46382/MJBAS.2021.5102

Copyright: (C2021 Daniel B. Zapanta Jr. et al. This is an open access article distributed under the terms of the Creative Commons Attribution License, which permits unrestricted use, distribution, and reproduction in any medium, provided the original author and source are credited.

Computer laboratories of educational institutions have increased the information technology infrastructure. However, it is very much exposed to several threats and vulnerabilities when it comes to the information that was kept in several workstations inside the laboratory. The study addressed the security issues in terms of the use of the computer laboratories using the barcode technology in regulating the entry point of the students and logging in the attendance log. It will only allow student users who were currently enrolled based on the schedule laboratory time and who has an account in mymu server.

Keywords: Access control, IT security, Computer laboratory, Attendance logs, Monitoring.

\section{Introduction}

Students use computers in the laboratory as part of the subject taken to conduct research, complete assignments, exercise laboratory activities, and interact with instructors and other students. Recently risk factors of computer laboratories of educational institutions have increased owing to the development of information technology and infrastructure [1]. Computer laboratories of the school are a typical place where workstations, the interconnecting network, and other devices are exposed continuously to several threats. On a large scale, risks can be traced back to the students' malicious and random actions. However, external threats cannot be excluded either.

In such situation, it is important to interpret properly the need for protection on different fields of information technology, not only the hardware security has to be ensured, but one should also cope with network communication and data security issues, as well as the vulnerabilities of the operating system have to be taken care of. Nevertheless, protection should be a priority in order to ensure the easy maintainability as well as the continuous availability of the workstations and the connected services.

Moreover, there are several technologies and methods for the security related design, management and maintenance of computer laboratories of educational institutions. In order to ensure the continuous availability and the proper maintainability it is crucial to protect the operating systems of the workstations as well as the whole network against internal and external attacks [2]. Cost is always an important factor that influences the procurement of tools and devices as well as the selection of applicable methods, especially in computer laboratories. However, there are other aspects of security like the short and long time effects of a successful harmful activity that should be also taken into consideration before a decision. Besides, even when someone has a reduced budget, there are always low-cost or even no-cost entry level options like the introduction of a security focused attitude, definition of a proper computer laboratory usage policy, etc. The study developed an access control and monitoring system that could contribute to the implementation of a safe, secure, and well maintainable computer laboratory. This study will use the barcode technology by regulating the entry point of a LAN client in 
computer laboratories connected to a local area network. The study will implement the access control and monitoring system to tighten the security of the LAN workstations with convenience. It monitors the activities of the users connected to the LAN by providing a real time view and user client's activity logs.

Based on the foregoing, it is therefore desirable to provide an access control and monitoring system, which accordingly can systemize the knowledge of the laboratory in-charge such that common problems can be detected, isolated and fixed by generating a report before such problems become critical. A lot of students were complaining to the laboratory in-charge when workstations inside the laboratory were not working.

Any student can use the computer laboratory even if not enrolled in the laboratory subject. Some of them take something such as memory, mouse, keyboard, etc. from the laboratories and change the settings of the workstation. There is no monitoring or record keeping of students who used the computer unit in the laboratory. If there is a damaged computer unit or any untoward lost or incidents in the laboratory, there is no record for the last student user in a particular workstation.

The objective of the study is to develop an access control and monitoring system which utilize the usage of barcode technology to improve effective and efficient security system. Notwithstanding the study aims:

- To place a barcode reader near the entrance door access system and class attendance system using student ID for the access.

- To design and develop Graphical User Interface (GUI) software to input student profile will be stored in a database and can be used by the entrance door access system and class attendance system.

- To keep a record of student who utilize the workstation in the laboratories.

\section{Related Literature}

Computer laboratory users upload and share content in the websites [11] or within the laboratory workstations and sometimes changed the settings of each computer unit and can even view other workstation content.

Securing the physical access could serve as a first step towards the ideal protection level of the computer laboratories. One can control the group of people entering a computer laboratory using possession based authentication like magnetic access cards, smart cards, barcode technology, etc. or knowledge based authentication such as a PIN number reader based solution $[3,4,5]$. The advantage of possession based authentication tools are that they are usually cheap and can be immediately disabled when they are stolen or lost.

The study is a premise of "Computer Lab Management System Web Application" by GeorgiOssipov [7]. The system is designed for managing computers used for software testing. The computers, known as hosts, can be either a physical machine or a virtual one which will be run on the user's computer and grants access via TCP/IP [12]. The main function of the develop application was to be able to reserve certain host for testing software functionality and to keep track of Host's software licenses and IP addresses configured for those hosts. The computer lab management system helps the system administrator to keep track of all the available resources (e.g. 
networks, servers, storage, applications and services) [16] and point physical machines on which they are hosted. Thus, Computer laboratory management was created to support the testing in remote sites [13].

Laboratory Management System by Hasral Harfizal Bin Mohd Zait [8] is an application that manages several tasks of Faculty of System and Software Engineering (FSKKP) laboratories at University Malaysia Pahang (UMP). All of the laboratories are equipped with the Laboratory Management System in accessing the laboratory facilities by the registration made by the faculty to the said class [14].

Cyber Cafe Management System by Dhanoop Bhaskar and Ashrafi Osama $[9,10]$ is a software package which can be used in cyber cafes for managing client's computer efficiency. The objective of the software is to maintain the details of the users, cabins, and login history. It provides the facility of prepaid and postpaid accounts respectively, for Account users and walk-through users. It has features like adding, viewing, editing of user details, cabin details, recharge option for prepaid users, billing, tariff settings, etc. After they are logout the time and amount will be automatically generated at the server module and the bill is provided to the user.

The study of Borrero and Marquez [15] developed augmented reality-based lab system that enabled teachers and students to work remotely (Internet/intranet) in current classroom laboratories, including virtual elements which interact with real ones.

Research done by Xu et al. [17] and Achuthan et al. [20] on the use of virtual laboratory helped students understand and solved real-world problems with sufficient laboratory resources and improved efficiency. It makes use of hardware located in different physical locations, VMWare software to manage the virtual resources and NetLab+ to manage the configuration of multiple different virtual scenarios [19].

Naidoo and Naidoo [18] focused on blended learning in mathematics using computer laboratory to create a learning environment that promoted interactive learning by giving projects together with traditional teaching.

The literature and studies presented and discussed were all relevant to the research study of system development "Access Control and Monitoring System for Computer Laboratory". However, the system differed from those cited is more reliable and effective because of the hybrid features that enhances the system.

\section{Methodology}

The study utilized the developmental research method which is accomplished using Systems Development Life Cycle (SDLC) Methodology used by Chakraborty et al. [1] with modification which has been defined as the systematic study of designing, developing, and evaluating computer programs, process, and products to meet the criteria of internal consistency and effectiveness. Generally, an SDLC Methodology follows these steps which will address the problem stated in this study: (1.) If there is an existing system, its deficiencies are identified. Recently, Misamis University has mymu website that allows the students to view their grades and to update on their bill of payment. (2.) The new system requirements are defined. To maximize the use of mymu account, the study will utilize the existing system in the access control and monitoring of computer laboratory usage. (3.) The proposed system is designed. Plans are created, including programming and security issues. (4.) The new system is 
developed. The new components and programs must be obtained and installed. (5.) The system is put into use. The flow of the proposed system is presented in Figure 1.

A computer laboratory usage policy defines when, how and by whom laboratory resources can be used. Its positive effect is that it creates a clear situation by defining possibilities and boundaries. Elements of this rule collection are stated in the policies and procedure manual [6].

Providing these systems in the computer laboratories will tighten the security and monitoring of the activities inside the laboratories. The role of the user is to provide data for attendance logs in order to access the laboratory resources. Attendance logs are based on the information given by the barcode data. The system will checked if the student is currently enrolled in the computer laboratory. If enrolled, the system will checked the schedule of the student if it coincides with the time of the laboratory time. Once it is authenticated as a registered user, the student can now open and used the workstation. Unregistered user information such as ID number will be denied by the system. If the student is not enrolled or not yet on the scheduled time of the class, the student was still allowed to seat-in and use the resources inside the laboratory.

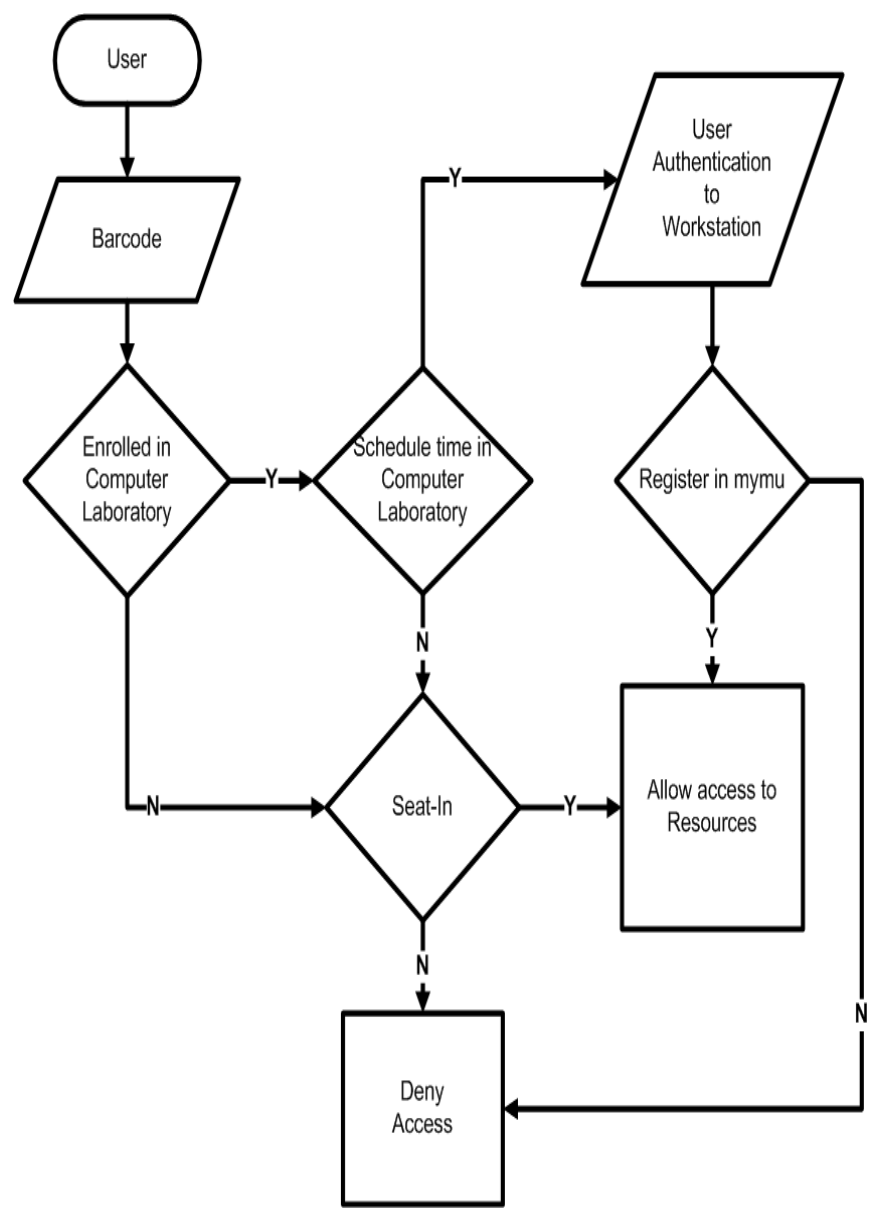

Fig.1. The flow of access control and monitoring on the computer laboratory

In this perspective software design and development is viewed as an activity whose goal is to produce a tool that is expected to have an effect to the security and access level. The design will be grounded in some learning theory which gives the framework for the software design (the requirements). Some software of this kind does incorporate 
elements of a security and access strategy, but these are embedded in a framework which is explicit in the software. From the designer's or a developer's perspective, the arena of security and access is in the interaction and behavior of the students as users of the computer laboratories. The barcode reader, which was placed on the monitoring computer served as the first device to accept input data which was converted as attendance logs. This attendance logs was based on the information stored in the barcode data of the user's identification card. The attendance station was then connected to the mymu server, via a switch/ hub, which checked the username and password of the user who wanted to use the computer laboratory resources. The monitoring computer acted as the controller for the different client station in the computer laboratory. The client station has an interface intended for time blocking, which serves as the main module for client station access control. This kind of architecture can be presented in Figure 2.

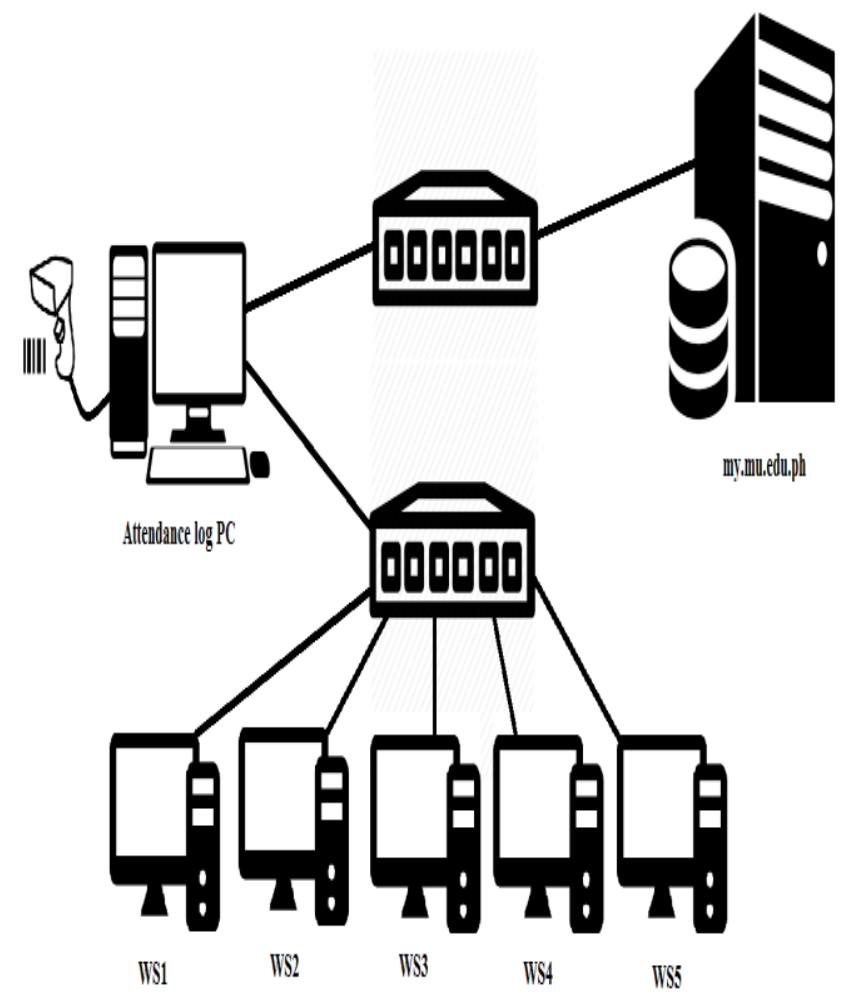

Fig.2. Architectural design of the study

\section{Results and Discussions}

Monitoring the users of computer laboratory is very important in terms of the usage of the different resources inside. In Misamis University, the students were having computer class wherein they are going to get inside the room if it is already their scheduled class time. However, there are also students who will be using the computer laboratory even if they are not enrolled on the subject. With that, the usage of the resources is not properly monitor as well as the access of the computer unit because everyone can use it. With the implementation of the study, it will help in the control of student users inside the computer laboratory and monitor the resources used.

The system started with the use of a barcode reader in reading the student identification which will be read by the monitoring computer which is run in order to allow the student to access the laboratory. Once the ID is read, the 
student can now use the workstation inside the laboratory. Figure 3 presented the graphical user interface of access control for laboratory.

\begin{tabular}{|c|c|c|c|}
\hline \multicolumn{2}{|l|}{ 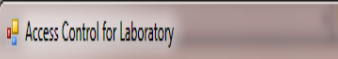 } & & 0.8 \\
\hline \multicolumn{4}{|l|}{ logs } \\
\hline \multicolumn{2}{|l|}{ ID number: } & \multicolumn{2}{|c|}{ Date and Time: 10/20/2016 12:25:25 PM } \\
\hline Workstation & ID number & User & Status \\
\hline , HF304-WS1 & 1500769 & ERQUUITA, CHLOE & Class \\
\hline HF304-W52 & 1501240 & HIBAYA, TRACY & Class \\
\hline HF304-WS3 & 1500804 & GENERALAO, JEROME & Seat-In \\
\hline HF304-WS4 & 1501927 & ECHALICO, RYAN AN... & Class \\
\hline HF304-W55 & 1101320 & ABAY, LUNINGNING & Class \\
\hline HF304-W56 & 1500640 & ABATAYO, MERCY & Seat-In \\
\hline HF304-W57 & 1501013 & TERO, GEORGE & Class \\
\hline HF304-W58 & 1500284 & SAQUIN, REY & Class \\
\hline HF304-W59 & 1402081 & SABELLANO, BEEEN & Class \\
\hline HF304-WS10 & 9132200 & RUPINTA, PATRICK & Class \\
\hline HF304-WS11 & 1500137 & BURBURAN, ABRAHAM & 1 Class \\
\hline HF304-WS12 & 1500060 & PONGASE, ALLAN & Class \\
\hline HF304-WS13 & 1500721 & BALURAN,LENIE & Class \\
\hline HF304-WS14 & 1500367 & URDANETA, JUANTO. & . Class \\
\hline HF304-WS15 & 1501108 & OLIVAR, MAGDALENE & Class \\
\hline
\end{tabular}

Fig.3. Graphical user interface of access control for laboratory

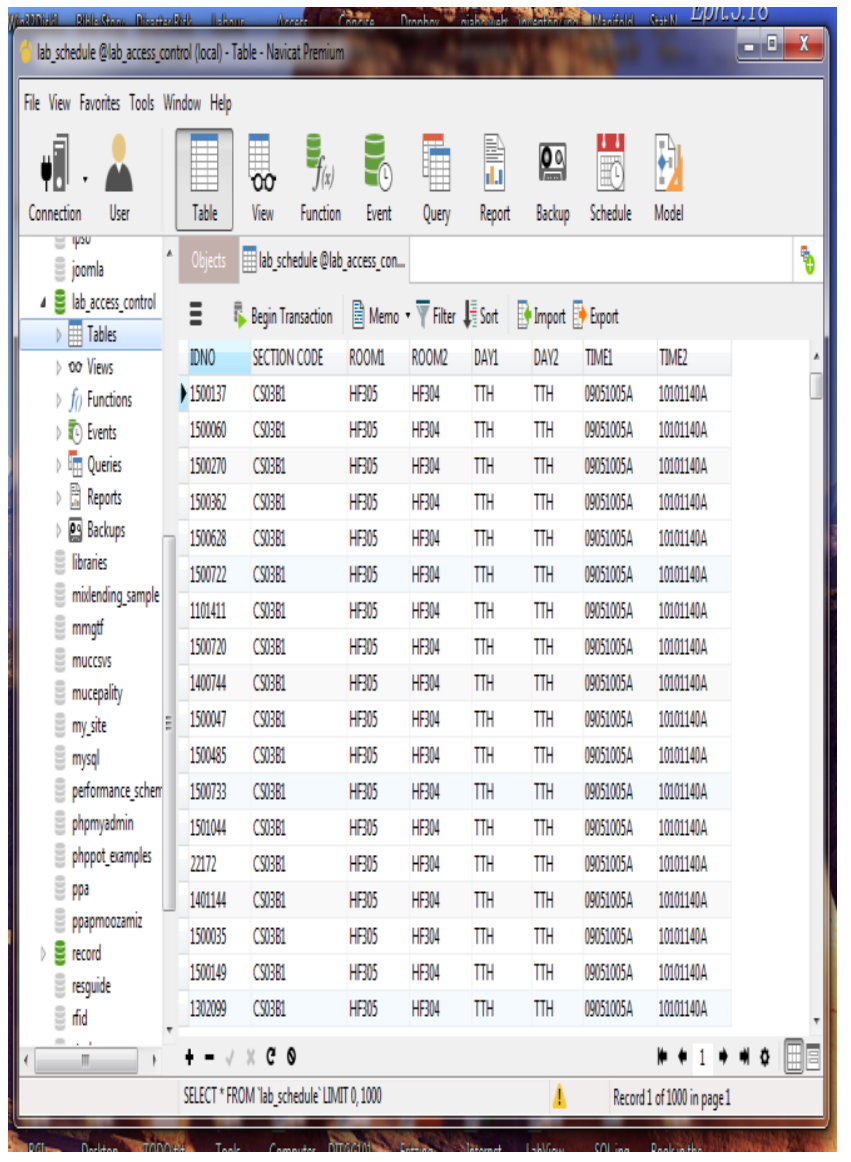

Fig.4. Access Control and Monitoring

Database

Figure 4 presented the database of the access control for laboratory. It contained the logs of the users of laboratory resources. Figure 5 presented the user's authentication in the workstation using username and password. The user cannot access any application in the workstation unless the username and password entered matches to the mymu server.

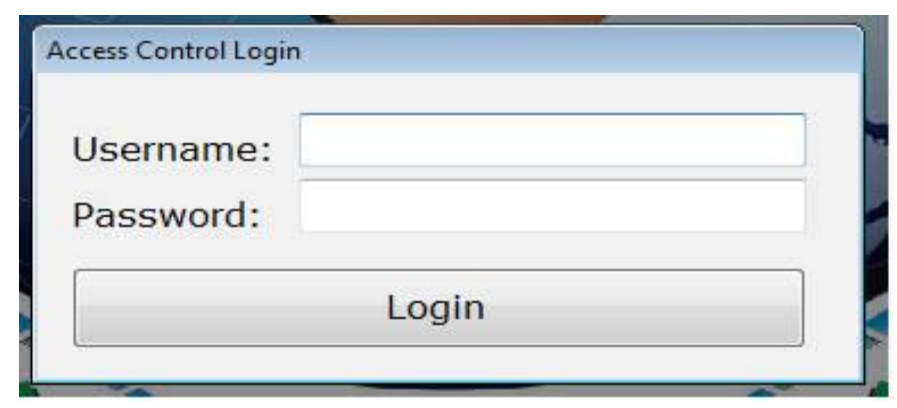

Fig.5. Access Control Login

Figure 6 presented the mymu account of students where username and password entered in the access control login is checked whether it matched or not. 


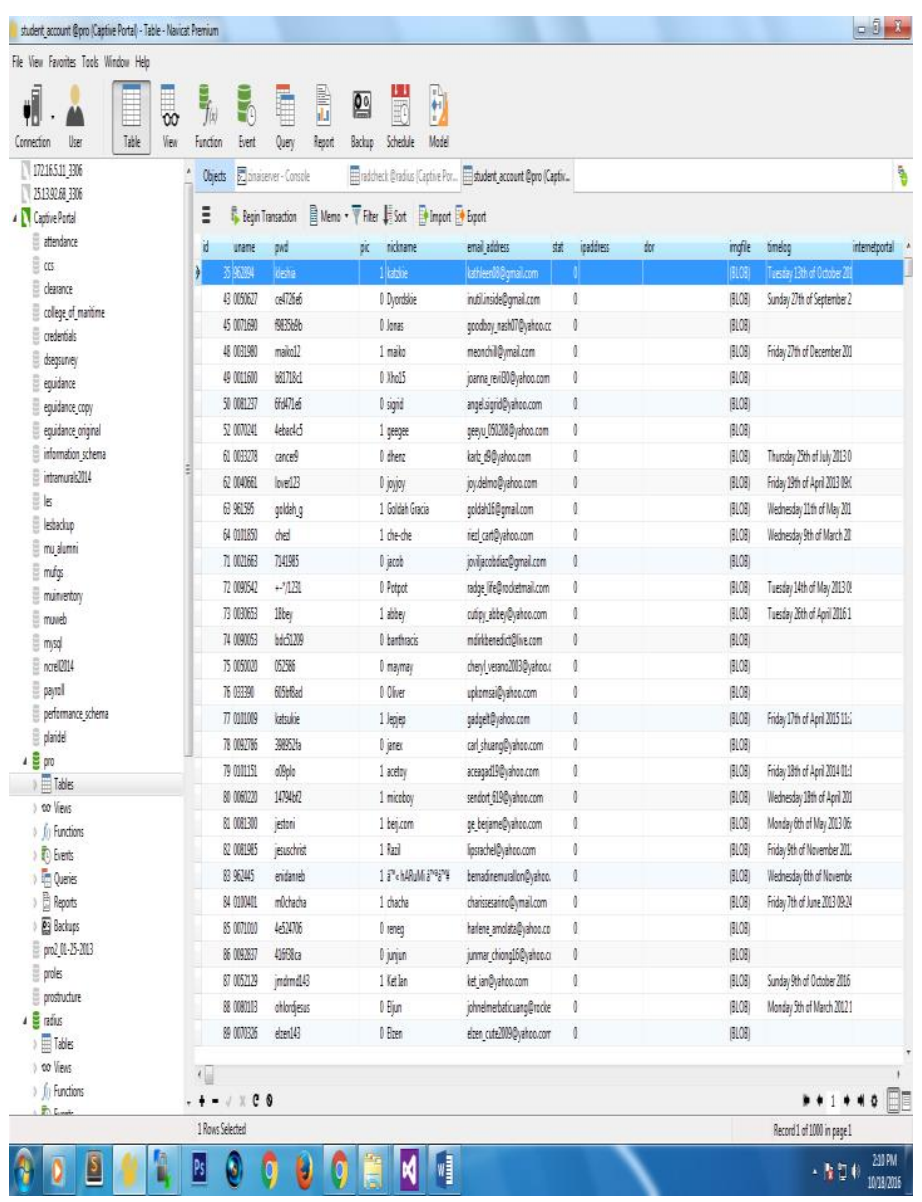

Fig.6. mymu account

Figure 7 presented the PHP codes that were being invoked to check whether the username and password entered by the user in the access control login matches to the mymu account.

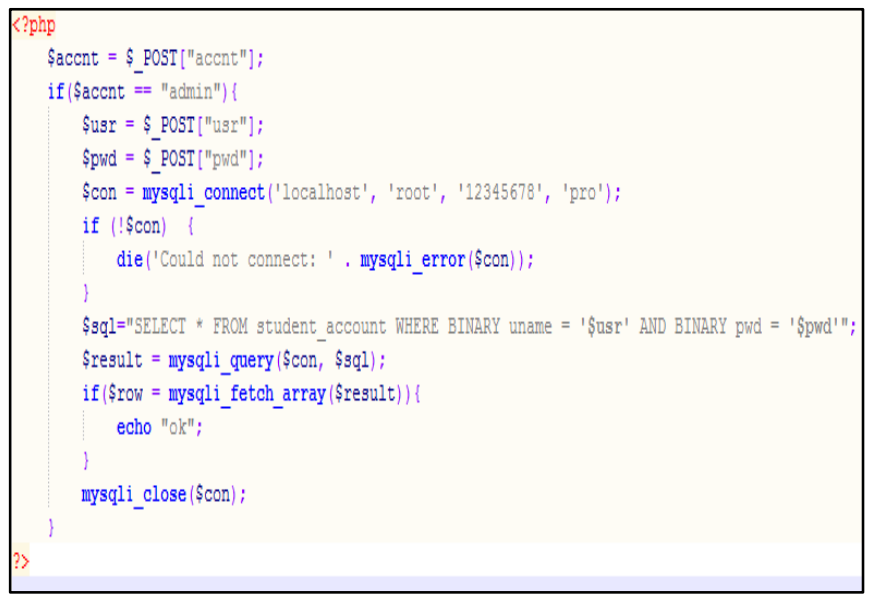

Fig.7. PHP codes in checking username and password

Figure 8 presented the visual basic codes that will manipulate the PHP code found in the mymu server. The purpose of this code is to invoke the PHP code that checks the username and password of the user. The subroutine check_user checks the username and password of the user. The subroutine check_schedule checks whether the user is currently enrolled on the class schedule. 


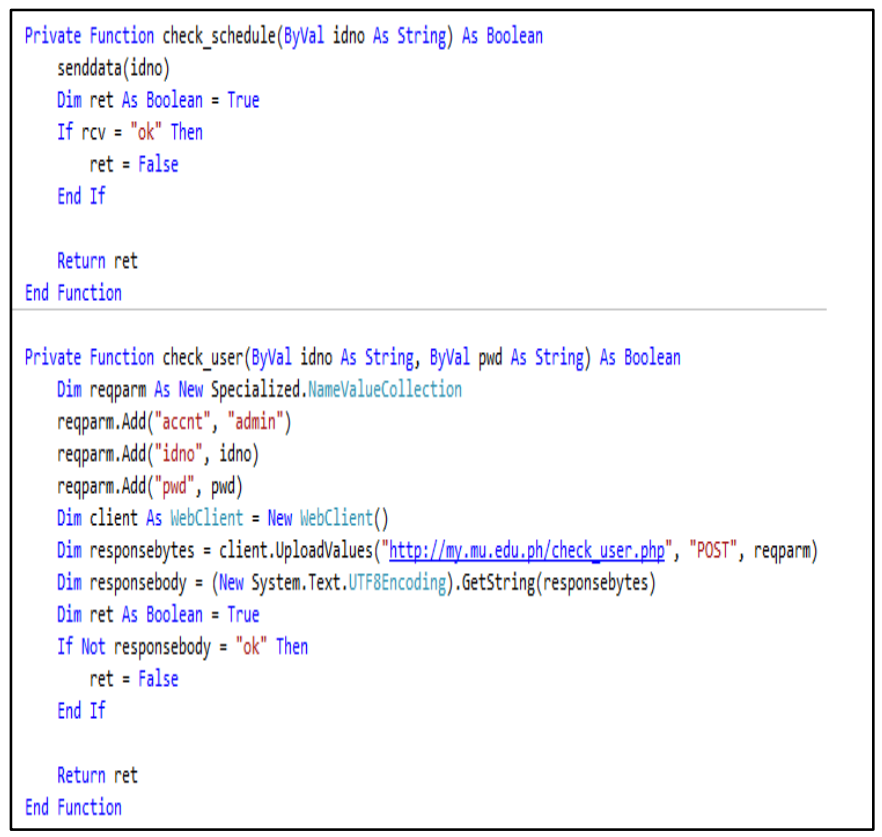

Fig.8. Visual Basic code that will grant the user to access

Figure 9 presented the report generated by the monitoring computer that shows the logs of users including the status of use which is class or seat-in.

\begin{tabular}{|c|c|c|c|c|c|c|}
\hline \multicolumn{6}{|c|}{ Report Logs } & \begin{tabular}{ll|l} 
& $x$ & $x$ \\
\end{tabular} \\
\hline \multirow{2}{*}{\multicolumn{2}{|c|}{$\begin{array}{l}\text { Section Code: } \\
\text { Room: }\end{array}$}} & $\operatorname{Cs} 03 \mathrm{~B} 1$ & - & Date: $10 / 20 / 2016$ & 아 & \\
\hline & Room: & HF304 & r & Time: $10101140 \mathrm{~A}$ & r & Print: \\
\hline \multicolumn{3}{|c|}{ Workstation } & ID number & User & Status & \\
\hline \multirow[t]{15}{*}{ p } & HF304-WS1 & & 1500769 & ERQUITA, CHLOE & Class & \\
\hline & HF304-WS2 & & 1501240 & HIBAYA, TRACY & Class & \\
\hline & HF304-WS3 & & 1500804 & GENERALAO, JEROME & Seat-In & \\
\hline & HF304-WS4 & & 1501927 & ECHALICO, RYAN AN... & Class & \\
\hline & HF304-WS5 & & 1101320 & ABAY, LUNINGNING & Class & \\
\hline & HF304-WS6 & & 1500640 & ABATAYO, MERCY & Seat-In & \\
\hline & HF304-WS7 & & 1501013 & TERO, GEORGE & Class & \\
\hline & HF304-WS8 & & 1500284 & SAQUIN, REY & Class & \\
\hline & HF304-WS9 & & 1402081 & SABELLANO, BELEN & Class & \\
\hline & HF304-WS1 & & 9132200 & RUPINTA, PATRICK & Class & \\
\hline & HF304-WS1 & & 1500137 & BURBURAN, ABRAHAM & Class & \\
\hline & HF304-WS1 & & 1500060 & PONGASE, ALLAN & Class & \\
\hline & HF304-WS1 & & 1500721 & BALURAN,LENIE & Class & \\
\hline & HF304-WS1 & & 1500367 & URDANETA, JUANITO... & Class & \\
\hline & HF304-WS1 & & 1501108 & OLIVAR, MAGDALENE & Class & \\
\hline
\end{tabular}

Fig.9. Report on users' logs

\section{Conclusions and Recommendations}

Computer laboratory as one of the facilities in every university or colleges helped students to do hands-on activities. There are several resources found in the laboratory which assist students in their projects, online activities, and even online quiz or exams. In the computer laboratory of Misamis University, there is a ratio of 1 student for 1 computer which means every student held responsible in the use of the computer unit during their scheduled time. Supposedly, only those students who are enrolled with a laboratory class can enter and use the laboratory. However, since there is no strict monitoring on the use of laboratory, students may use the resources 
even if they are not enrolled or not yet their scheduled time. Problems like the change of desktop settings and other configuration, loss of computer peripherals arise due to lack of monitoring the laboratory users. With the implementation of the developed system which is to provide barcode technology for the entrance of the students and the authentication of students enrolled subjects for the laboratory use, the researcher created a system that provide logs of the student who use the computer unit and other resources inside the laboratory. There is a balance in access control and monitoring of laboratory resources since student will just be using one account in the laboratory entrance using their mymu account. The system was capable of generating report of student who use the laboratory in terms of the last computer user, identifying the type of student user as to seat-in or class-enrolled.

Organizations that had computer laboratories should utilize the developed system in order to strengthen the security of the users of the laboratory resources.

For future work, the researcher would like to recommend on monitoring the application that runs in the workstation, inventory on the features of the workstation and the activities done by the users.

\section{References}

[1] Mohammed, N. M., Niazi, M., Alshayeb, M., \& Mahmood, S. (2017). Exploring software security approaches in software development lifecycle: A systematic mapping study. Computer Standards \& Interfaces, 50, 107-115.

[2] Karpov, A. O. (2017). Education for knowledge society: Learning and scientific innovation environment. Journal of Social Studies Education Research, 8(3), 201-214.

[3] He, W., Golla, M., Padhi, R., Ofek, J., Dürmuth, M., Fernandes, E., \& Ur, B. (2018). Rethinking access control and authentication for the home internet of things (IoT). In 27th \{USENIX\} Security Symposium (\{USENIX\} Security 18) (pp. 255-272).

[4] V. Ajanovski, Access Control and Monitoring for Campus Computer Labs. Best Practice Document, 2015. [Online]. Available: http://services.geant.net/cbp/Knowledge_Base/Campus_Networking/Documents/CBP-12 access-control-and-monitoring_final.pdf. [Accessed: 20-Oct- 2020].

[5] M. Khosrow-Pour, Encyclopedia of Information Science and Technology, Third Edition, Information Resources Management Association, USA, 2014. [Online]. Available: http://kilyos.ee.bilkent.edu.tr/ billur /publ_list/encyc14.pdf. [Accessed: 18- Nov- 2020].

[6] MU-CALC-LIM, 2015. Quality Management System Policies \& Procedure Manual. Misamis University, Ozamiz City, Computer Application Laboratory Center Clause 7.2.4

[7] G. Ossipov, Computer Lab Management System Web Application, Theseus.fi, 2014. [Online]. Available: https://www.theseus.fi/bitstream/handle/10024/85145/Thesis.pdf?sequence=1. [Accessed: 20- Dec- 2020].

[8] Paul, P. K., \& Aithal, P. S. (2018). Cyber Security to Information Assurance: The Changing World of Cyber Sciences. system.

[9] Hakkeem, K. M. (2020). Cyber cafe management system for PC park internet cafe. 
[10] A. Osama, Cyber Cafe Management - College Essay - 1462 Words,StudyMode, 2012. [Online]. Available: http://www.studymode.com/course-notes/Cyber-Cafe-Management-1445890.html. [Accessed: 15- Nov- 2016].

[11] Ouaddah, A., Mousannif, H., Abou Elkalam, A., \& Ouahman, A. A. (2017). Access control in the Internet of Things: Big challenges and new opportunities. Computer Networks, 112, 237-262.

[12] Poliakov, M., Henke, K., \& Wuttke, H. D. (2018). The augmented functionality of the physical models of objects of study for remote laboratories. In Online engineering \& Internet of Things (pp. 151-159). Springer.

[13] Di Giamberardino, P., \& Temperini, M. (2017, May). Adaptive access to robotic learning experiences in a remote laboratory setting. In 2017 18th International Carpathian Control Conference (ICCC) (pp. 565-570). IEEE. [14] Schauer, F., Ožvoldová, M., Gerža, M., Krbeček, M., Beňo, P., Komenda, T., \& Archibong, M. I. (2017). REMLABNET IV-LTI federated remote laboratory management system with embedded multiparameter simulations. International Journal of Online Engineering.

[15] Tirado-Morueta, R., Sánchez-Herrera, R., Márquez-Sánchez, M. A., Mejías-Borrero, A., \& Andujar-Márquez, J. M. (2018). Exploratory study of the acceptance of two individual practical classes with remote labs. European Journal of Engineering Education, 43(2), 278-295.

[16] Miyachi, C. (2018). What is "Cloud"? It is time to update the NIST definition?. IEEE Cloud Comp. (3), 6-11. [17] Hu, X., Le, H., Bourgeois, A. G., \& Pan, Y. (2018, October). Collaborative Learning in Cloud-based Virtual Computer Labs. In 2018 IEEE Frontiers in Education Conference (FIE) (pp. 1-5). IEEE.

[18] Bognar, L., Fáncsikné, É. H., Horvath, P., Joos, A., Nagy, B., \& Strauber, G. (2018). Improved learning environment for calculus courses. Journal of Applied Technical and Educational Sciences, 8(4), 35-43.

[19] Kumar, V., \& Sharma, D. (2017). Cloud computing as a catalyst in STEM education. International Journal of Information and Communication Technology Education (IJICTE), 13(2), 38-51.

[20] Nedungadi, P., Ramesh, M. V., Pradeep, P., \& Raman, R. (2018). Pedagogical support for collaborative development of virtual and remote labs: Amrita VLCAP. In Cyber-physical laboratories in engineering and science education (pp. 219-240). Springer, Cham. 